\title{
Corrigendum
}

\section{Effects of Risperidone Augmentation in Patients with Treatment-Resistant Depression: Results of Open-Label Treatment Followed by Double-Blind Continuation}

\author{
Mark Hyman Rapaport, Georges M Gharabawi, Carla M Canuso, Ramy A Mahmoud, Martin B Keller, \\ Cynthia A Bossie, Ibrahim Turkoz, Robert A Lasser, Amy Loescher, Philippe Bouhours, Fiona Dunbar \\ and Charles B Nemeroff
}

Neuropsychopharmacology (2006) 31, 25 I4. doi:I0.1038/sj.npp. 1301218

Correction to: Neuropsychopharmacology (2006) 31, 2505-2513. doi:10.1038/sj.npp.1301113

Dr Nemeroff consults to, serves on the Speakers' Bureau and/ or Board of Directors, has been a grant recipient, and/or owned equity in one or more of the following: Abbott Laboratories, Acadia Pharmaceuticals, AFSP, APIRE, AstraZeneca, BMC-JR LLC, Bristol-Myers Squibb, CeNeRx, Corcept, Cypress Biosciences, Cyberonics, Eli Lilly, Entrepreneur's Fund, Forest Laboratories, George West Mental Health Foundation, GlaxoSmithKline, i3 DLN, Janssen Pharmaceutica, Lundbeck, NARSAD, Neuronetics, NIMH, NFMH, NovaDel Pharma, Otsuka, Pfizer Inc., Quintiles, Reevax, UCB Pharma, Wyeth.

Dr Keller consults to, serves on the Speakers' Bureau and/or Board of Directors, has been a grant recipient of one or more of the following: Abbott Laboratories, BristolMyers Squibb, Cephalon, Collegium, Cypress Biosciences, Cyberonics, Eli Lilly, Forest Laboratories, GlaxoSmithKline, Janssen Pharmaceutica, Merck Inc., Mitsubishi Pharma, Novartis, Organon, Otsuka, Pfizer Inc., Pharmastar, SanofiSynthelabo, Scirex, Sepracor, Somerset Pharmaceuticals, Vela Pharmaceuticals, Wyeth.

Dr Rapaport consults to, serves on the Speakers' Bureau and/or Board of Directors, has been a grant recipient, in one or more of the following: AstraZeneca, Braincells Inc., Corcept, Cyberonics, Eli-lilly, Forest Laboratories, Glaxo SmithKline, Janssen Pharmaceutica, Neurocrine Biosciences, NIMH, NIDA, NCCAM, Novartis, Pharmacia Upjohn, Pfizer Inc., Roche, Sanofi-Synthelabo, Solvay, Stanley Foundation, Sumitomo, Wyeth, UCB Pharma. 